medication. Baseline sweat chloride was recorded, and repeated at 2 months. Baseline pulmonary function, height and weight were recorded and repeated at monthly visits for 3 months.

Results To date 24 of 27 suitable subjects have commenced Ivacaftor. Mean $\mathrm{FEV}_{1} \%$ predicted was $64.3 \%$ predicted at Ivacaftor commencement and mean BMI was $22.1 \mathrm{~kg} / \mathrm{m}^{2}$. Mean $\mathrm{FEV}_{1}$ percent predicted increased in absolute terms by $8.9 \%$ at 1 month and $8.7 \%$ at 3 months ( $\mathrm{p}<0.001$ at both time points). Mean BMI improved to $22.7 \mathrm{~kg} / \mathrm{m}^{2}$ at 1 month and $23.0 \mathrm{~kg} / \mathrm{m}^{2}$ at 3 months ( $\mathrm{p}=0.002,0.003$ respectively). There was a significant fall in sweat chloride at 2 months (median 114 to 51 $\mathrm{mmol} / \mathrm{L}, \mathrm{p}<0.001)$. Improvement in sweat chloride was not correlated in absolute or relative terms with improvements in pulmonary function or BMI. Four subjects with a mean absolute $\mathrm{FEV}_{1}$ improvement of $14.5 \%$ had sweat chloride responses not meeting pre-specified criteria at 2 months. Two of these subjects had a subsequent repeat test meeting continuation criteria. In one subject a suboptimal response was attributed to the omission of a single dose.

Conclusions The use of sweat chloride as a surrogate for clinical efficacy and a criterion for drug continuation is not supported by this data. Sweat chloride may be a marker of $100 \%$ adherence to therapy.

\section{P103 CULTURE AND CULTURE INDEPENDANT IDENTIFICATION OF BACTERIAL COMMUNITIES IN THE CYSTIC FIBROSIS RESPIRATORY TRACT}

${ }^{1} \mathrm{GG}$ Einarsson, ${ }^{2} \mathrm{McCaughan},{ }^{3} \mathrm{AA}$ Fodor, ${ }^{3} \mathrm{MC}$ Wolfgang, ${ }^{4} \mathrm{MM}$ Tunney, ${ }^{5} \mathrm{JS}$ Elborn; ${ }^{1} \mathrm{CF}$ and Airways Microbiology Research Group, Queen's University Belfast, Belfast, United Kingdom; ' ${ }^{2}$ Department of Medical Microbiology, Royal Group of Hospitals, Belfast, United Kingdom; ${ }^{3}$ University of North Carolina at Chapel Hill, Chapel Hill, United States of America; ${ }^{4}$ School of Pharmacy, Queen's University Belfast, Belfast, United Kingdom; ${ }^{5}$ Centre for Infection and Immunity, Queen's University Belfast, Belfast, United Kingdom

\subsection{6/thoraxjnl-2013-204457.253}

Introduction and Aims The identification of complex chronic polymicrobial infections, such as those observed in the cystic fibrosis (CF) airways, are often a diagnostic challenge. Few studies have compared culture-dependent methods with molecular identification making it hard to describe bacterial communities in a comprehensive manner. The aim of the study is to compare four different methods with respect to their similarities and differences in detection of bacteria.

Methods We compared41 sputum samples fromroutine clinicalculture, extended-culture (aerobic and anaerobic), and molecular identification such as Roche 454-FLX Titanium and T-RFLP to assess concurrence between methodologies in detecting bacteria. The agreement between methodologies in detecting either absence or presence of bacterial taxa was assessed by Kappa ( $\kappa)$ statistics.

Results The majority of bacterial taxa identified by culture were also identified with molecular analysis. In total 2, 60, 25, and 179 different bacterial taxa were identified with clinical-culture, extended-culture, T-RFLP and 454-FLX respectively. Clinicalculture, extended-culture and T-RFLP were poor predictors of species richness when compared to 454-FLX ( $\mathrm{p}<0.0001$ ). Agreement between methods for detecting Pseudomonas sp. and Burkholderia sp. was good with $\kappa \geq 0.7[\mathrm{p}<0.0001]$ and $\kappa \geq$ 0.9 [p $<0.0001]$ respectively. Detection of anaerobic bacteria, such as Prevotella sp. and Veillonella sp., was moderate between extended-culture and 454-FLX with $\kappa=0.461$ [p $<0.0001$ ] and $\kappa=0.311[\mathrm{p}=0.032]$ respectively, and good between TRFLP and 454-FLX with $\kappa=0.577[\mathrm{p}<0.0001]$ and $\kappa=0.808[\mathrm{p}<0.0001]$ respectively. Agreement between methods for other main bacterial taxa, such as Staphylcoccus sp. and Streptococcus sp., was poor with only a moderate agreement for detection of Streptococcus sp. observed between T-RFLP and 454-FLX $(\kappa=0.221[\mathrm{p}=0.024])$.

Conclusions This study demonstrates the increased sensitivity culture-independent microbial identification such as the 454FLX have over clinical-culture, extended-culture and T-RFLP methodologies. The extended-culture detected majority of the most prevalent bacterial taxa associated with chronic colonisation of the CF airways which were also detected by culture-independent methodologies. However, agreement between methods in detecting number of potentially relevant bacteria is largely lacking.

\section{P104 NEBULISED HYPERTONIC SALINE IMPROVES QUALITY OF LIFE IN ADULT PATIENTS WITH NON-CYSTIC FIBROSIS BRONCHIECTASIS}

K Bentley, ZL Borrill; North Manchester General Hospital, Manchester, UK

10.1136/thoraxjnl-2013-204457.254

Background Nebulised hypertonic saline (HTS) improved lung function, quality of life and exacerbation frequency in a study of patients with non-cystic fibrosis (CF) bronchiectasis ${ }^{1}$. It may improve chest clearance by increasing water content of airway surface liquid, enhancing mucociliary clearance. A protocol was developed for the use of HTS in a district hospital setting. Safety, tolerability, lung function and quality of life data are presented.

Methods Patients with non-CF bronchiectasis were assessed on a locally developed chest clearance pathway consisting of active cycle breathing technique, postural drainage, flutter device and mucolytic. Patients with ongoing symptoms were given a trial dose of $4 \mathrm{mls}$ HTS $7 \%$ with spirometry measured pre and post. Patients continued on $4 \mathrm{mls}$ HTS od/bd for 12 months if tolerated. Adverse effects, quality of life and spirometry was collected at 4 weeks and 6 months. Data were compared using paired $t$ tests.

Results 34 patients (mean age 62, 25 female, mean $\mathrm{FEV}_{1}$ 66\% predicted) were assessed. $2(6 \%)$ patients did not proceed with treatment due to (a. $\mathrm{FEV}_{1}$ decline $>15 \%$ and b. severe nausea).

\begin{tabular}{|c|c|c|c|c|c|}
\hline $\begin{array}{l}\text { Leicester Cough } \\
\text { Questionnaire }\end{array}$ & $\begin{array}{l}\text { Pre HTS } \\
\text { Mean (SD) }\end{array}$ & $\begin{array}{l}4 / 52 \\
\text { Mean (SD) }\end{array}$ & $\begin{array}{l}p \\
\text { value }\end{array}$ & $\begin{array}{l}6 / 12 \\
\text { Mean (SD) }\end{array}$ & $\begin{array}{l}p \\
\text { value }\end{array}$ \\
\hline Physical & $3.7(1.4)$ & $4.1(1.4)$ & $0.002^{*}$ & $4.0(1.5)$ & 0.28 \\
\hline Psychological & $4.2(1.7)$ & $4.8(1.4)$ & $0.001^{*}$ & $4.7(1.6)$ & 0.28 \\
\hline Social & $4.1(1.9)$ & $4.7(1.6)$ & $0.001^{*}$ & $4.6(1.7)$ & 0.20 \\
\hline TOTAL & $11.8(4.6)$ & $13.7(4.3)$ & $0.0003^{*}$ & $13.3(4.5)$ & 0.15 \\
\hline $\begin{array}{l}\text { St Georges } \\
\text { Respiratory } \\
\text { Questionnaire }\end{array}$ & $\begin{array}{l}\text { Pre HTS } \\
\text { Mean (SD) }\end{array}$ & & \multicolumn{2}{|c|}{$\begin{array}{l}6 / 12 \\
\text { Mean (SD) }\end{array}$} & $\begin{array}{l}p \\
\text { value }\end{array}$ \\
\hline Symptoms & $83.2(14.2)$ & & \multicolumn{2}{|l|}{$74.6(19.0)$} & $0.02^{*}$ \\
\hline Activity & $78.0(22.5)$ & & \multicolumn{2}{|l|}{$68.7(27.0)$} & 0.14 \\
\hline Impact & $57.2(18.7)$ & & \multicolumn{2}{|l|}{$43.7(22.9)$} & $0.07^{\star}$ \\
\hline TOTAL & $67.8(18.7)$ & & \multicolumn{2}{|l|}{$56.1(20.7)$} & $0.01^{*}$ \\
\hline
\end{tabular}

